\title{
Investigation of Electrochemical Dissolving the Amorphous and Nanocrystal Alloys by a Rotating Disk Electrode
}

\author{
Konstantin Rakhimyanov ${ }^{1}$, Maria Ivanova ${ }^{1,}{ }^{*}$ and Andrey Rakhimyanov ${ }^{1}$ \\ ${ }^{1}$ Novosibirsk State Technical University, Faculty of Mechanical Engineering and Technologies \\ 630073 Prospekt K. Marks, 20, Novosibirsk, Russia
}

\begin{abstract}
The electrochemical processing characterized by the absence of force and heat effect on the processed material provides favorable conditions for maintaining unique properties of amorphous and nanocrystal alloys during processing. Understanding the peculiarities of the electrochemical dissolving of the material is possible in studying anode polarization characteristics. The investigations of the anode dissolving of alloys 5BDSR and $82 \mathrm{~K} 3 \mathrm{HSR}$ conducted before showed the presence of diffusion limitations connected with the absence of the reaction products removal from the processing zone and supply a new portion of reacting substances. To eliminate the limitations, it is necessary to conduct investigations of the anode behavior by the moving electrolyte which is provided by the rotating disk electrode. It allows controlling the process of ion transfer due to the changes in the anode rotation speed and providing the accessibility of the working sample surface for the electrochemical action. The paper presents the results of polarization investigations of the anode dissolving by using the method of the rotating disk electrode in 10 $\%$ neutral solutions of salts $\mathrm{NaNO}_{3}, \mathrm{Na}_{2} \mathrm{SO}_{4}$ and $\mathrm{NaCl}$. It is established that the dissolving process in the stationary and movable electrolytes is characterized by the presence of zones of slowdown of the anode dissolving process. After providing the electrolyte motion in the processing zone, it became possible to increase the value of the current density.
\end{abstract}

\section{Introduction}

Alloys with the amorphous structure in comparison with the traditional construction materials possess a unique physical (small losses for remagnetization) and mechanical (high hardness) properties as well as high corrosive resistance [1 - 5]. It determines the working characteristics of details made of these alloys.

For investigated amorphous (82K3HSR) and nanocrystal (5BDSR) alloys the reasons which determine the impossibility of their processing by traditional methods are high

\footnotetext{
* Corresponding author: m.ivanova.2010@stud.nstu.ru
} 
made of these materials present alternate layers of amorphous tapes (with a thickness of 20 - $30 \mu \mathrm{m}$ ) and of nondurable binding material. It causes additional limitations in choosing the forming methods of such constructions. In choosing the processing method it is also necessary to take into consideration the fact that the alloy $82 \mathrm{~K} 3 \mathrm{HSR}$ during heating to a temperature of $470^{\circ}$ loses its unique magnetic properties $[6,7]$.

Taking into account these limitations, it can be said that the electrochemical processing, which is characterized by the absence of heat and force effect on the processed material, is considered as one of the possible technological processing methods $[8,9]$.

It is known that the speed of the material electrochemical dissolving is determined not only by the mode parameters but also by the choice of the electrolyte for processing a particular material. As amorphous alloys are a new class of materials, there are no recommendations in scientific papers concerning the electrolyte composition for their electrochemical processing [10 - 12]. It is known that aqueous neutral salt solutions are the most widely used during the electrochemical processing. So, $10 \%$ aqueous solutions of non-organic salts such as sodium chloride, sodium sulphate and sodium nitrate were chosen as electrolytes.

The investigations [13] on the anode dissolving of alloys 82K3HSR and 5BDSR by the potentiodynamic method conducted before revealed the presence of the diffusion limitations connected with the absence of the reaction product removal from the processing zone and the supply of a new portion of the reacting substances. To study this limitation, it is necessary to conduct investigations of the anode behavior with the moving electrolyte. The method of the rotating disk electrode used in this case allows controlling the process of ion transfer due to the change in the rotation speed [14 - 16].

The paper under consideration is devoted to assessing the anode behavior of alloys 82K3HSR and 5BDSR with the moving electrolyte by using the method of the rotating disk electrode.

\section{Methods of Experimental Research}

To conduct polarization investigations by the method of the rotating disk electrode, an installation was designed and manufactured, the scheme of which is presented in Figure 1. The installation design consists of frame 6 with objective table 2 with electrochemical cell 1 fixed on it which comprises investigated sample 3 fixed in dielectric holder 14. The control unit of the direct current engine 12 consists of current rectifier 11 and tachometer 8 connected with the engine shaft. There are three electrodes in the cell - additional (copper) 4, comparison (platinum) 5 and working (the investigated sample) 3, which are connected with the potentiometer 10 . The gap between the comparison electrode and the anode is regulated by displacing the sliding gear 13 .

The polarized investigations were conducted with a potential change and in the value range of $0 \mathrm{~V}$ to $12 \mathrm{~V}$ at a speed of $100 \mathrm{mV} / \mathrm{s}$ in $10 \%$ salt solutions $\mathrm{NaNO}_{3}, \mathrm{Na}_{2} \mathrm{SO}_{4}$ and $\mathrm{NaCl}$. Studying the influence of the rotation speed of the disk electrode on the anode dissolving was made according to the dependence of the current density on the anode potential at different values of the rotation speed $(\sqrt{\omega})$ which were equal to $7.37,11.2$ and $13.7[\mathrm{rad} / \mathrm{s}]^{-\frac{1}{2}}$. The value of the inter-electrode gap between the comparison electrode and the anode surface constituted $0.1 \mathrm{~mm}$. 


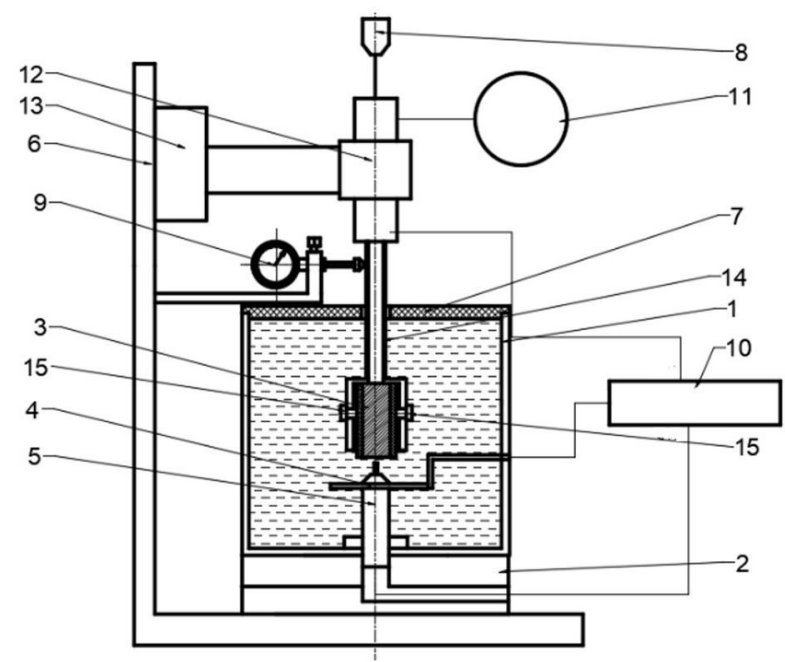

Fig. 1. Scheme of the experimental installation for conducting investigations by the method of the rotating disk electrode: 1 - cell; 2 - objective table; 3 - working electrode (anode); 4 - additional electrode (cathode); 5 - comparison electrode; 6 - frame; 7 - cell cover; 8 - tachometer; 9 - dial gauge; 10 - potentiometer-galvanostat Elins $\mathrm{P}$ - 20X ; 11 - current rectifier; 12 - direct current engine; 13 - sliding gear with micrometric displacement; 14 - dielectric muff; 15 - mounting bolt

\section{Results and Discussion}

The experimental results concerning the effect of the electrode rotation speed on the anode dissolving of alloys mentioned above in $10 \%$ solutions $\mathrm{NaNO}_{3}, \mathrm{Na}_{2} \mathrm{SO}_{4}$ and $\mathrm{NaCl}$ showed that the electrochemical dissolving was characterized by the presence of zones of the process slowdown. It should be noted that the polarization curves of the anode dissolving of amorphous alloy $82 \mathrm{~K} 3 \mathrm{HSR}$ in the moving electrolyte are similar to the curves obtained in the stationary electrolyte in all the investigated solutions. The electrolyte motion through the inter-electrode gap allowed increasing the value of the current density in $10 \% \mathrm{NaNO}_{3}$ from $19 \mathrm{~A} / \mathrm{cm}^{2}$ at $\sqrt{\omega}=0$ (Figure 2, curve 1) to $26 \mathrm{~A} / \mathrm{cm}^{2}$ at $\sqrt{\omega}=13,7[\mathrm{rad} / \mathrm{s}]^{-\frac{1}{2}}$ (Figure 2, curve 4) in the potential range to $5 \mathrm{~V}$. The zone of the material active dissolving in $10 \%$ solution $\mathrm{Na}_{2} \mathrm{SO}_{4}$ is in the potential range to $9 \mathrm{~V}$. In this case the value of the current density increased from $32 \mathrm{~A} / \mathrm{cm}^{2}$ at $\sqrt{\omega}=0$ (Figure 4, curve 1) to $59 \mathrm{~A} / \mathrm{cm}^{2}$ at $\sqrt{\omega}=13,7$ [rad/ $\mathrm{s}]^{-\frac{1}{2}}$ (Figure 4, curve 4). It must be pointed out that the character of the alloy anode behavior in the solution of sodium chloride differs from other electrolytes considered and is described in Paper [13]. The maximum values of the current density in $10 \%$ solution $\mathrm{NaCl}$ were observed at potential $6 \mathrm{~V}$ and were equal to $32 \mathrm{~A} / \mathrm{cm}^{2}$ at $\sqrt{\omega}=13,7[\mathrm{rad} / \mathrm{s}]^{-\frac{1}{2}}$ (Figure 6 , curve 4) and $18 \mathrm{~A} / \mathrm{cm}^{2}$ at $\sqrt{\omega}=0$ (Figure 6, curve 1). Thus, the implementation of the electrolyte hydrodynamics in the inter-electrode gap allowed eliminating the diffusion limitations connected with difficulties for supplying a new portion of reacting substances and removing the chemical reaction products. It must be noted that in increasing the potential to more than $5 \mathrm{~V}$ in $10 \% \mathrm{NaNO}_{3}$ (Figure 2), to $9 \mathrm{~V}$ in $10 \% \mathrm{Na}_{2} \mathrm{SO}_{4}$ (Figure 4) and to $6 \mathrm{~V}$ in $10 \% \mathrm{NaCl}$ (Figure 6), there is a reduction in the current density. It testifies the development of passivation phenomena connected with forming oxide films on the investigated surface, which are difficult to dissolve. 
The polarized curves of the anode dissolving for nanocrystal alloy 5BDSR in stationary and immovable electrolytes are of the same character. In this case, increasing the potential to $5 \mathrm{~V}$ in $10 \% \mathrm{NaNO}_{3}$ provides the growth in the current density to $8 \mathrm{~A} / \mathrm{cm}^{2}$ at $\sqrt{\omega}=13.7$ $[\mathrm{rad} / \mathrm{s}]^{-\frac{1}{2}}$ (Figure 3, curve 4) in comparison with $4 \mathrm{~A} / \mathrm{cm}^{2}$ at $\sqrt{\omega}=0$ (Figure 3, curve 1).

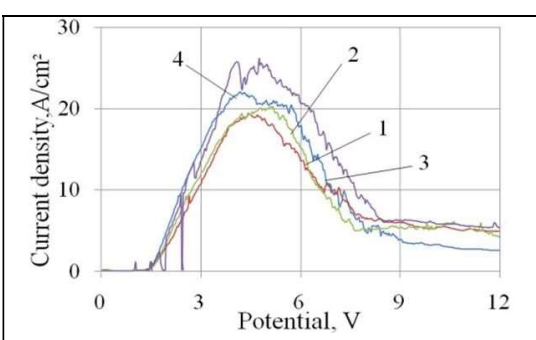

Fig. 2. Polarization curves of the anode dissolving of the alloy $82 \mathrm{~K} 3 \mathrm{HSR}$ in $10 \%$ $\mathrm{NaNO}_{3}: 1-\sqrt{\omega}=0 ; 2-\sqrt{\omega}=7.37[\mathrm{rad} /$ $\mathrm{s}]^{-\frac{1}{2}} ; 3-\sqrt{\omega}=11.2[\mathrm{rad} / \mathrm{s}]^{-\frac{1}{2}} ; 4-\sqrt{\omega}=$ $13.7[\mathrm{rad} / \mathrm{s}]^{-\frac{1}{2}}$

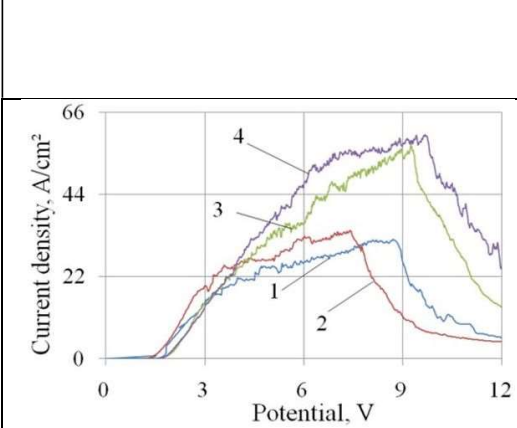

Fig. 4. Polarization curves of the anode dissolving of the alloy $82 \mathrm{~K} 3 \mathrm{HSR}$ in $10 \%$ $\mathrm{Na}_{2} \mathrm{SO}_{4}: 1-\sqrt{\omega}=0 ; 2-\sqrt{\omega}=$ $7.37[\mathrm{rad} / \mathrm{s}]^{-\frac{1}{2}} ; 3-\sqrt{\omega}=11.2[\mathrm{rad} /$ $\mathrm{s}]^{-\frac{1}{2}} ; 4-\sqrt{\omega}=13.7[\mathrm{rad} / \mathrm{s}]^{-\frac{1}{2}}$

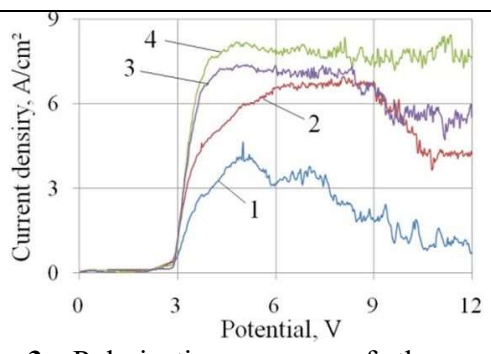

Fig. 3. Polarization curves of the anode dissolving of the alloy 5BDSR in $10 \%$ $\mathrm{NaNO}_{3}: 1-\sqrt{\omega}=0 ; 2-\sqrt{\omega}=$ $7.37[\mathrm{rad} / \mathrm{s}]^{-\frac{1}{2}} ; 3-\sqrt{\omega}=11.2[\mathrm{rad} /$ $\mathrm{s}]^{-\frac{1}{2}} ; 4-\sqrt{\omega}=13.7[\mathrm{rad} / \mathrm{s}]^{-\frac{1}{2}}$

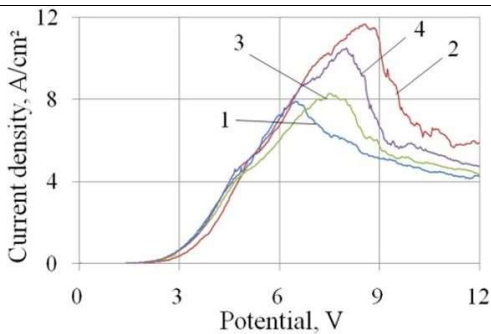

Fig. 5. Polarization curves of the anode dissolving of the alloy 5BDSR in $10 \%$ $\mathrm{Na}_{2} \mathrm{SO}_{4}: 1-\sqrt{\omega}=0 ; 2-\sqrt{\omega}=$ $7.37[\mathrm{rad} / \mathrm{s}]^{-\frac{1}{2}} ; 3-\sqrt{\omega}=11.2[\mathrm{rad} /$ $\mathrm{s}]^{-\frac{1}{2}} ; 4-\sqrt{\omega}=13.7[\mathrm{rad} / \mathrm{s}]^{-\frac{1}{2}}$

The value of the current density of anode dissolving the investigated material in $10 \%$ $\mathrm{Na}_{2} \mathrm{SO}_{4}$ in the potential range to $8 \mathrm{~V}$ increases from $8 \mathrm{~A} / \mathrm{cm}^{2}$ (Figure 5, curve 1) to 11 $\mathrm{A} / \mathrm{cm}^{2}$ (Figure 5, curve 2). It should be noted that the increase in the value of the current density from $2.2 \mathrm{~A} / \mathrm{cm}^{2}$ (Figure 7, curve 1) to $3.8 \mathrm{~A} / \mathrm{cm}^{2}$ (Figure 7, curve 4) in the potential range to $3 \mathrm{~V}$ is also observed in the electrolyte $10 \% \mathrm{NaCl}$. The further increase in the potential up to $12 \mathrm{~V}$ in electrolytes $\mathrm{Na}_{2} \mathrm{SO}_{4}$ and $\mathrm{NaNO}_{3}$ leads to decreasing the current density, which testifies the passivation of the surface investigated. Another character of the anode behavior can be seen in using the solution of sodium chloride [13]. 


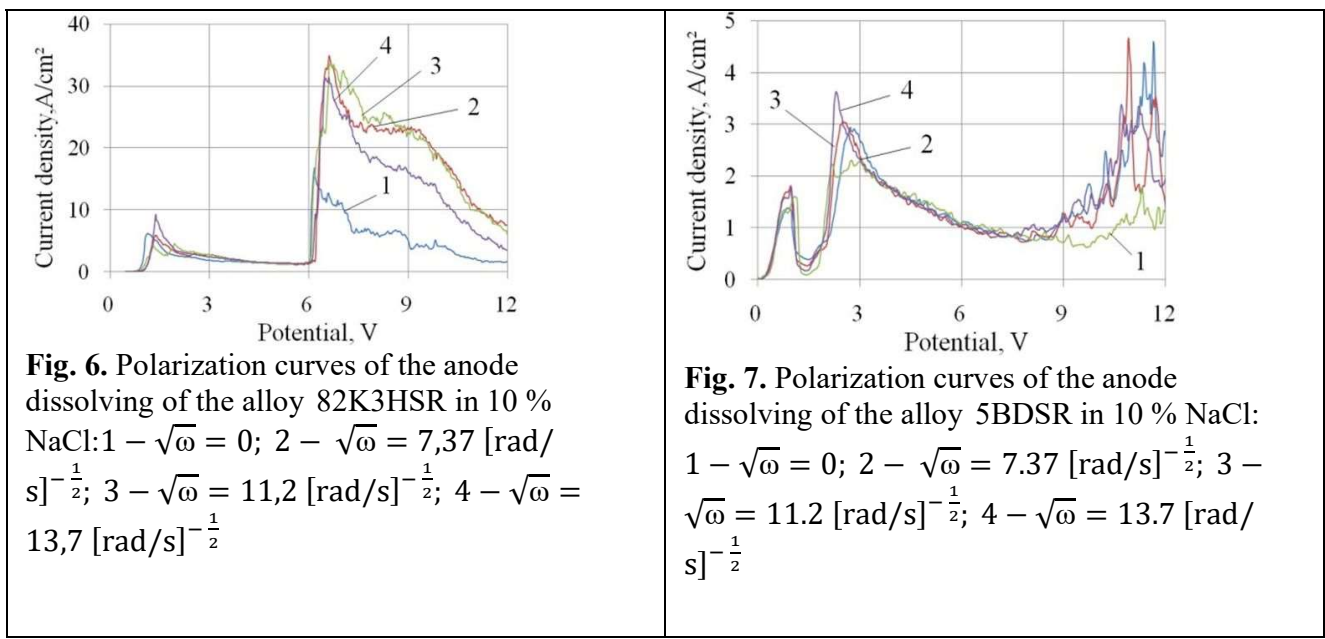

The implementation of the activating chlorine anions in the electrolyte solution displaces the start of the alloy active dissolving in the zone with fewer potentials. It may be connected with the fact that chlorine anions partly or fully push out oxygen from the passivating films on the anode surface, forming easily dissolvable compound $\left(\mathrm{FeCl}_{2}\right)$ in water. In this case the value of the current density reduces to $0.8 \mathrm{~A} / \mathrm{cm}^{2}$ (Figure 7, curves 1 -4 ) in the potential range from $3 \mathrm{~V}$ to $8 \mathrm{~V}$. The further increase in the potential to $12 \mathrm{~V}$ leads to growing the current density and is characterized by instability of the process.

\section{Conclusions}

The results of polarized investigations of the anode dissolving of alloys 82K3HSR and 5BDSR showed that the electrolyte motion in solutions $\mathrm{NaNO}_{3}, \mathrm{Na}_{2} \mathrm{SO}_{4}$ and $\mathrm{NaCl}$ led to increasing the current density, which testifies the running of electrochemical dissolving process in an active state. For the amorphous alloy $82 \mathrm{~K} 3 \mathrm{HSR}$ the highest current density was observed in $10 \% \mathrm{Na}_{2} \mathrm{SO}_{4}$, the value of which increased by 1.8 times (from $32 \mathrm{~A} / \mathrm{cm}^{2}$ at $\sqrt{\omega}=0$ to $59 \mathrm{~A} / \mathrm{cm}^{2}$ at $\left.\sqrt{\omega}=13.7[\mathrm{rad} / \mathrm{s}]^{-\frac{1}{2}}\right)$. For the nanocrystal alloy 5BDSR the highest increase in the current density could be seen in $10 \% \mathrm{NaNO}_{3}$ (from $4 \mathrm{~A} / \mathrm{cm}^{2}$ at $\sqrt{\omega}=0$ to 8 $\mathrm{A} / \mathrm{cm}^{2}$ at $\left.\sqrt{\omega}=7.37[\mathrm{rad} / \mathrm{s}]^{-\frac{1}{2}}\right)$. It is established that only diffusion limitations, which lead to slowing down the process of the anode dissolving, are eliminated in the moving electrolyte but the passivation phenomena connected with the formation of oxide films are not removed. To eliminate the limitations mentioned above it is necessary to search the corresponding mechanisms for activating the process of the anode dissolving.

\section{References}

1. X. L. Tian, C. W. Zhan, J. X. Hou, X. C. Chen, J. J. Sun, Journal of Materials and Technology, 26, 69 (2010)

2. G. Herser, Acta Materialia, 61, 718 (2013)

3. Yu I. Skorvanek, et al., Journal of Magnetism and Magnetic Materials, 215, 440 (2000)

4. P. Kwapuliski, et al., Journal of Materials Processing Technology, 157, 735 (2004)

5. D. Szewieczek, J. Tyrlik-Held, S. Lesz, Journal of Achievements in Materials and Manufacturing Engineering, 24, 87 (2007) 
6. T. Kulik, et al., Journal of Materials Processing Technology, 162, 215 (2005)

7. G. Buttino, A. Cecchetti, M. Poppi, Journal of Magnetism and Magnetic Materials, 172, 147 (1997)

8. G. Benke, W. Gnot, Hydrometallurgy, 64, 205 (2002)

9. V. V. Yanpolsky, B. A. Krasilnikov, K. KH. Rakhimyanov, Applied Mechanics and Materials, 698, 321 (2014)

10. R. Schuster, et al., Science, 289, 98 (2000)

11. K. P. Rajurkar, M. M. Sunbaram, A. P. Malshe, Procedia CIRP, 6, 13 (2013)

12. G. Mayank, Ch. Fuchen, K. Masanori, Procedia CIRP, 68, 511 (2018)

13. K. K. Rakhimyanov, M. V. Ivanova, S. I. Vasilevskaya, MATEC Web of Conferences, 01012 (2018)

14. W. Natsu, T. Ikeda, M. Kunieda, Precision Engineering, 31, 33 (2007)

15. V. M. Volgin, A. D. Davydov, Electrochimical Acta, 259, 56 (2018)

16. S. U. Sapkal, P. S. Jagtap, Procedia Manufacturing, 20, 119 (2018) 